Supporting Information for:

\title{
A New Method to Synthesize Complicated Multi-Branched Carbon Nanotubes with Controlled Architecture and Composition
}

Dacheng Wei, Yunqi Liu,* Lingchao Cao, Lei Fu, Xianglong Li, Yu Wang, Gui Yu, and Daoben Zhu*

Key Laboratory of Organic Solids, Institute of Chemistry, Chinese Academy of Sciences, Beijing 100080, P.R. China

E-mail: liuyq@mail.iccas.ac.cn

\section{Supplemental Figures}

Figure S1. TEM image of the tip of MBCNTs indicating that the thin tips are closed-ended.

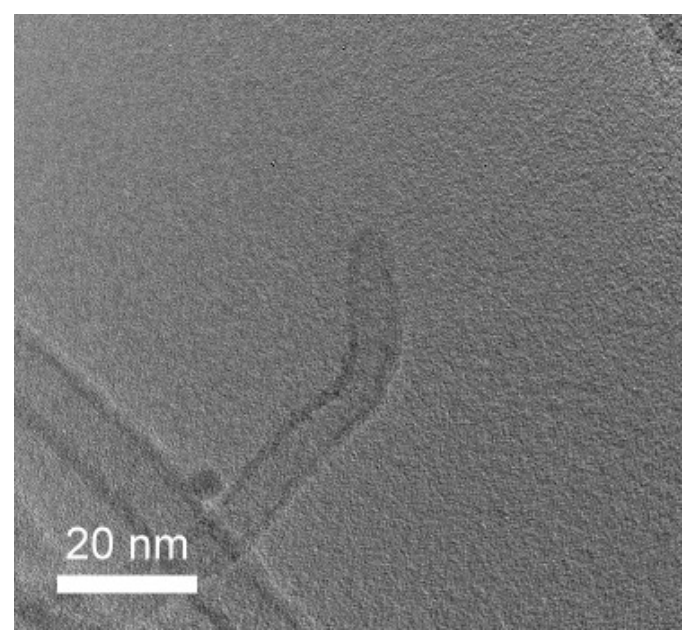

Figure S2. SEM image of an array of CNTs without branched junctions. This array is synthesized in the steady flow of $40 \mathrm{sccm} \mathrm{H}_{2}$ without flow-fluctuation.

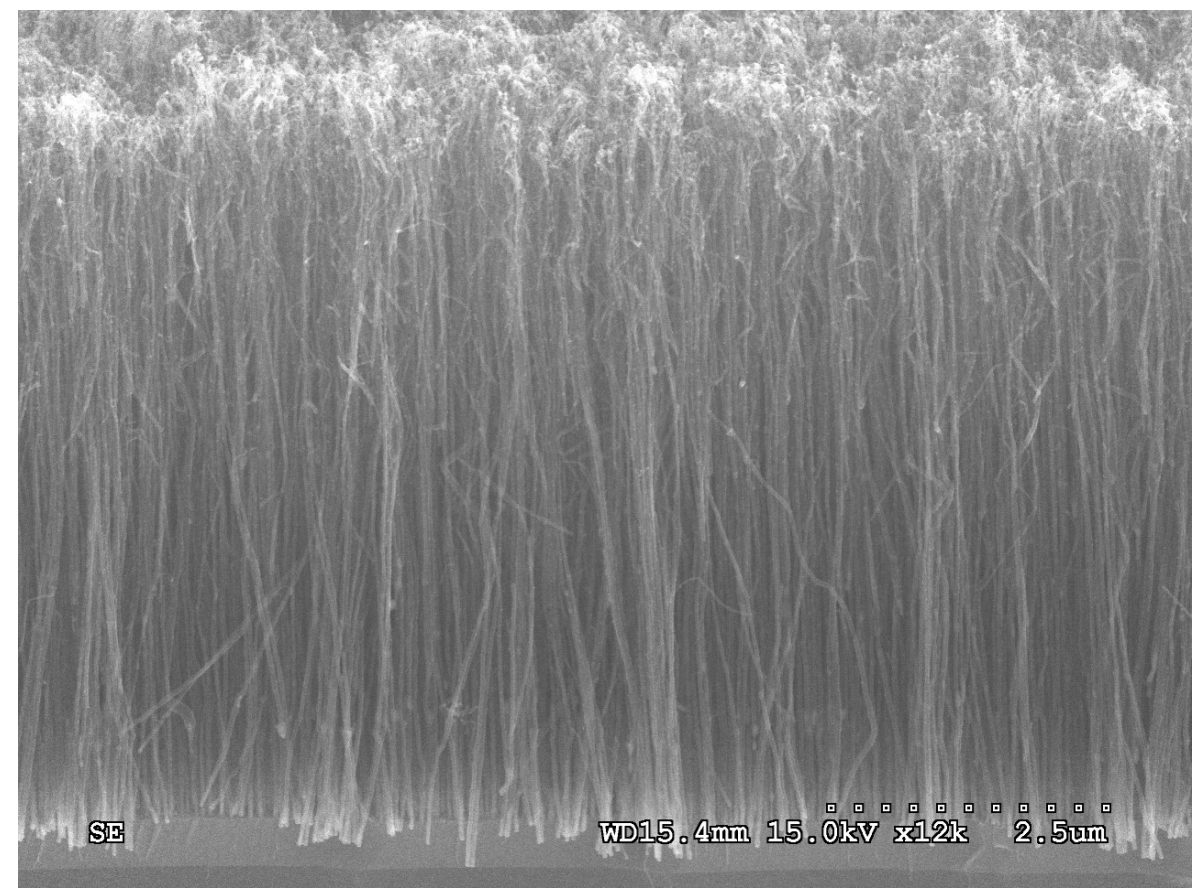


Figure S3. SEM image of MBCNTs arrays synthesized by a continuous flow-fluctuation process in the growth. The branched junctions distribute all positions of CNTs. The white circles indicate the positions of branched junctions.

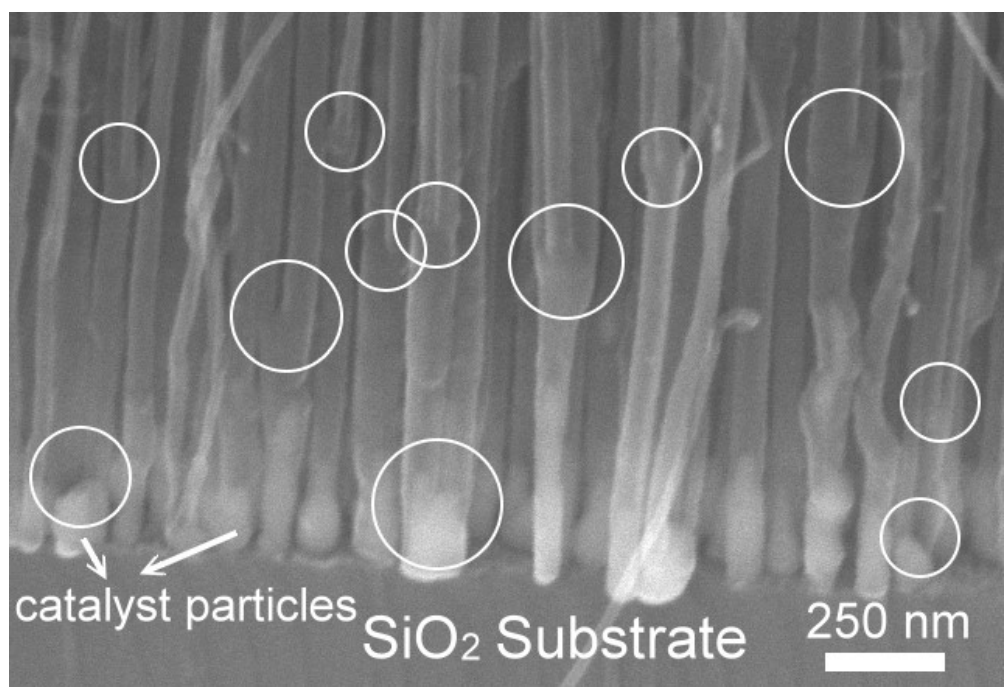

Figure S4. SEM images of arrays of branched CNTs. There is a parallel interface of branched junctions in the arrays. The insets are the magnified images, in which the branched junctions are contoured in white lines for clarity.

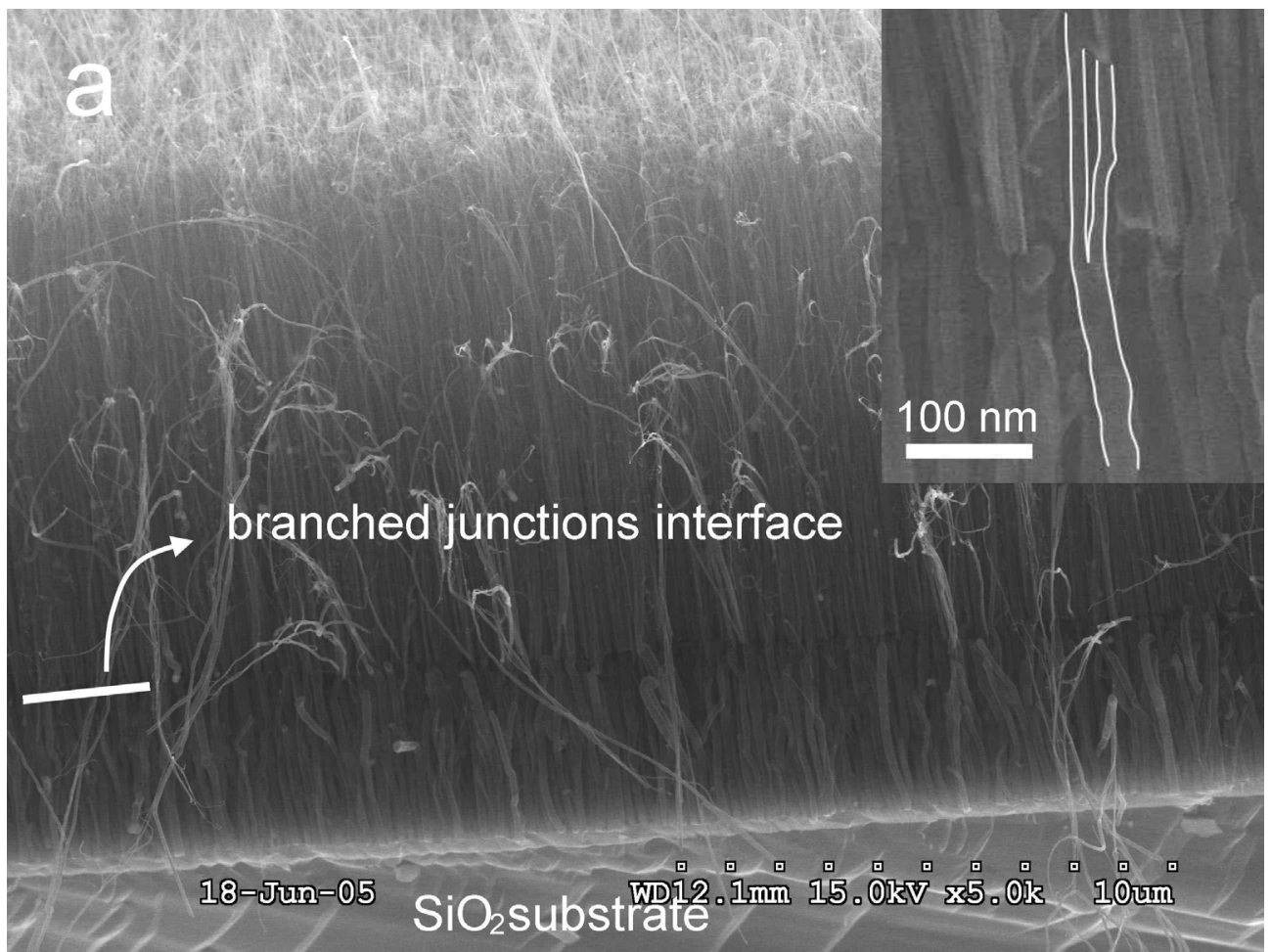




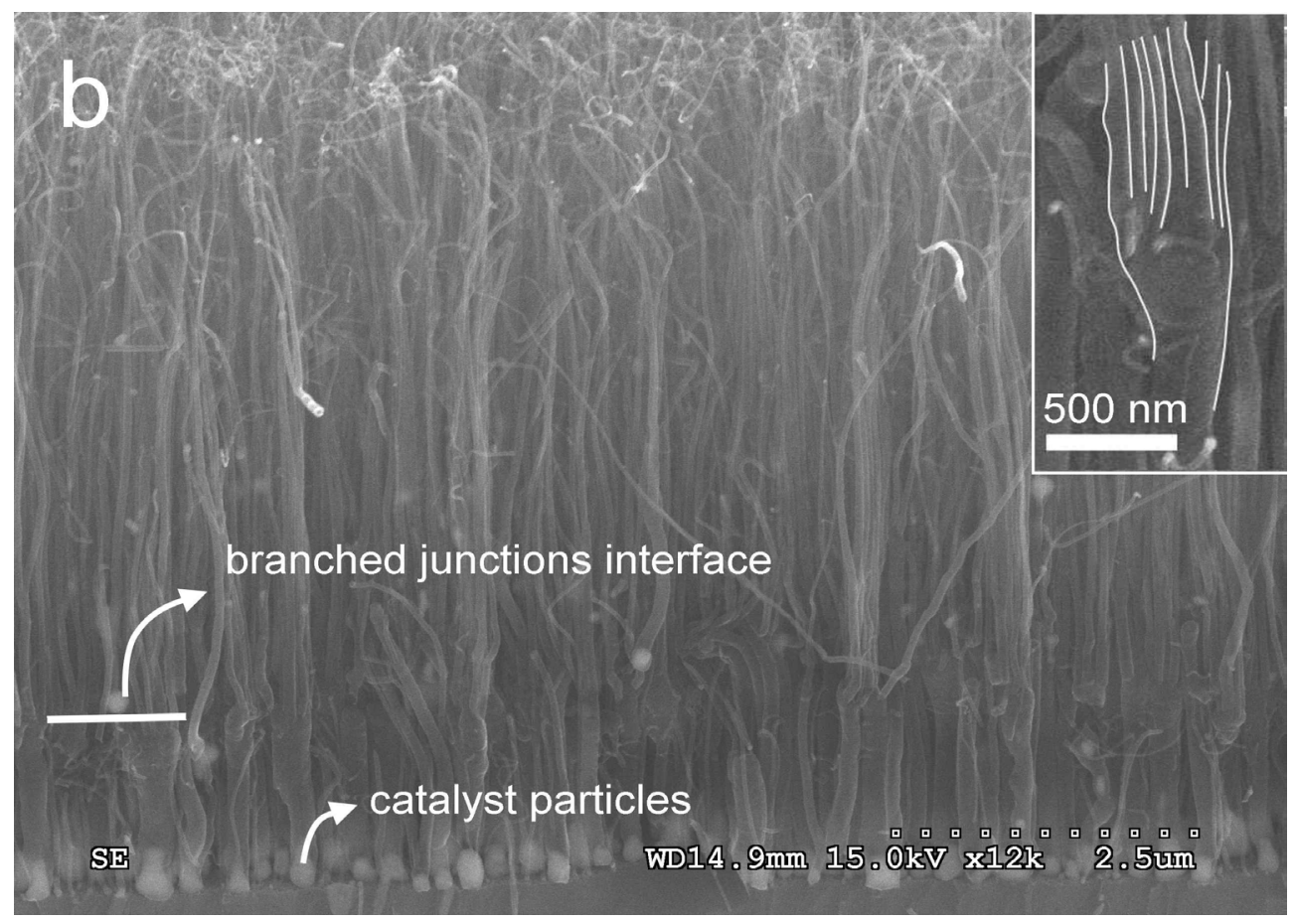

Figure S5. TEM images of the product at the 2nd (a), 4th (b), 10th (c) and 15th (d) minute of the reaction in which gas-flow fluctuations continuously. The white circles indicate the positions of branched junctions.

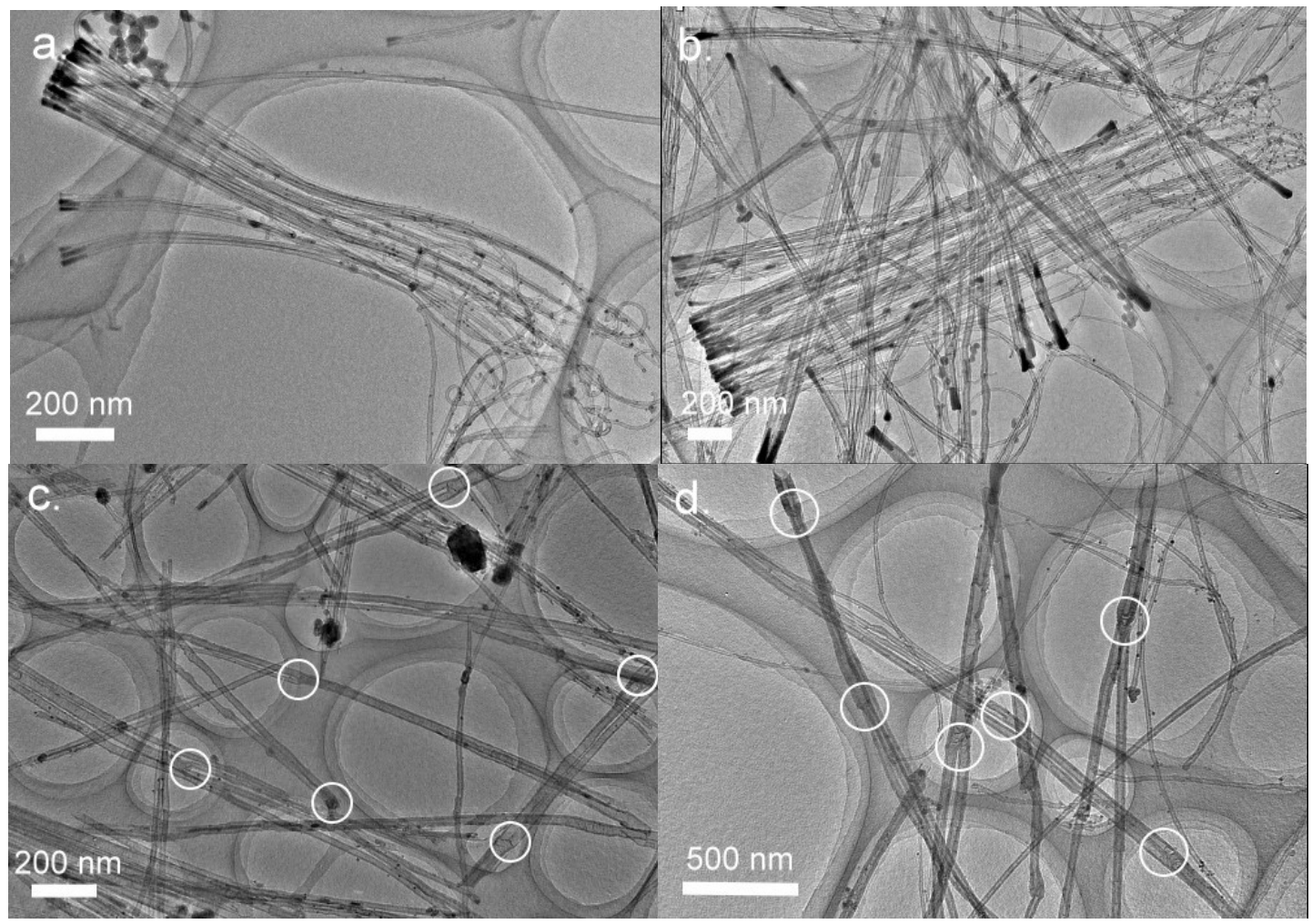


Figure S6. TEM images of multilevel branched junctions. The intervals of flow-fluctuation for each multilevel branched junction are 1 minute (a), 2 minutes (b) and 3 minutes (c).

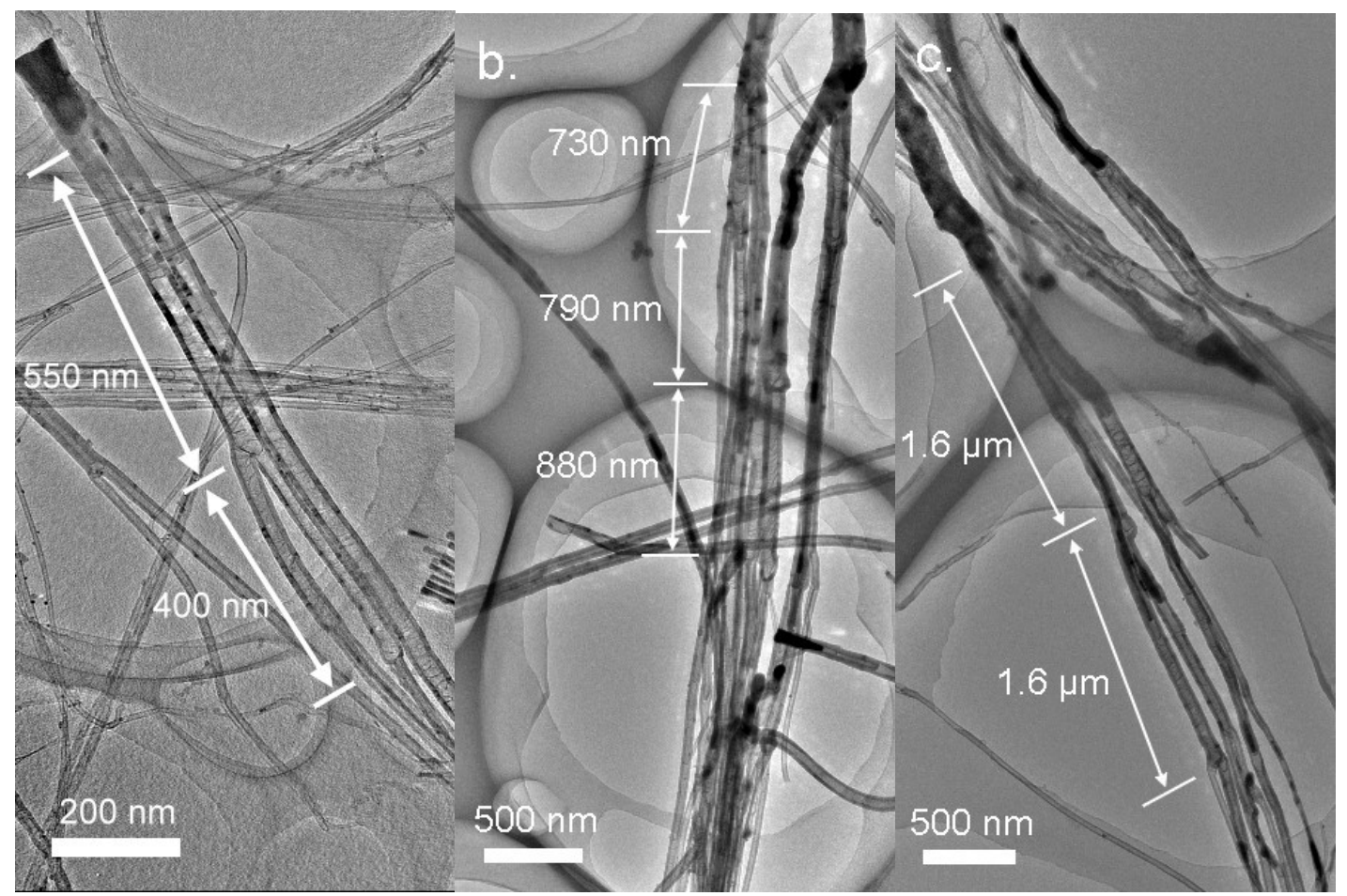

Figure S7. EELS spectra of a typical $\mathrm{C} / \mathrm{CN}_{\mathrm{x}}$ branched junctions, which are taken from two regions, the $\mathrm{N}$-doped stems and the undoped branches.

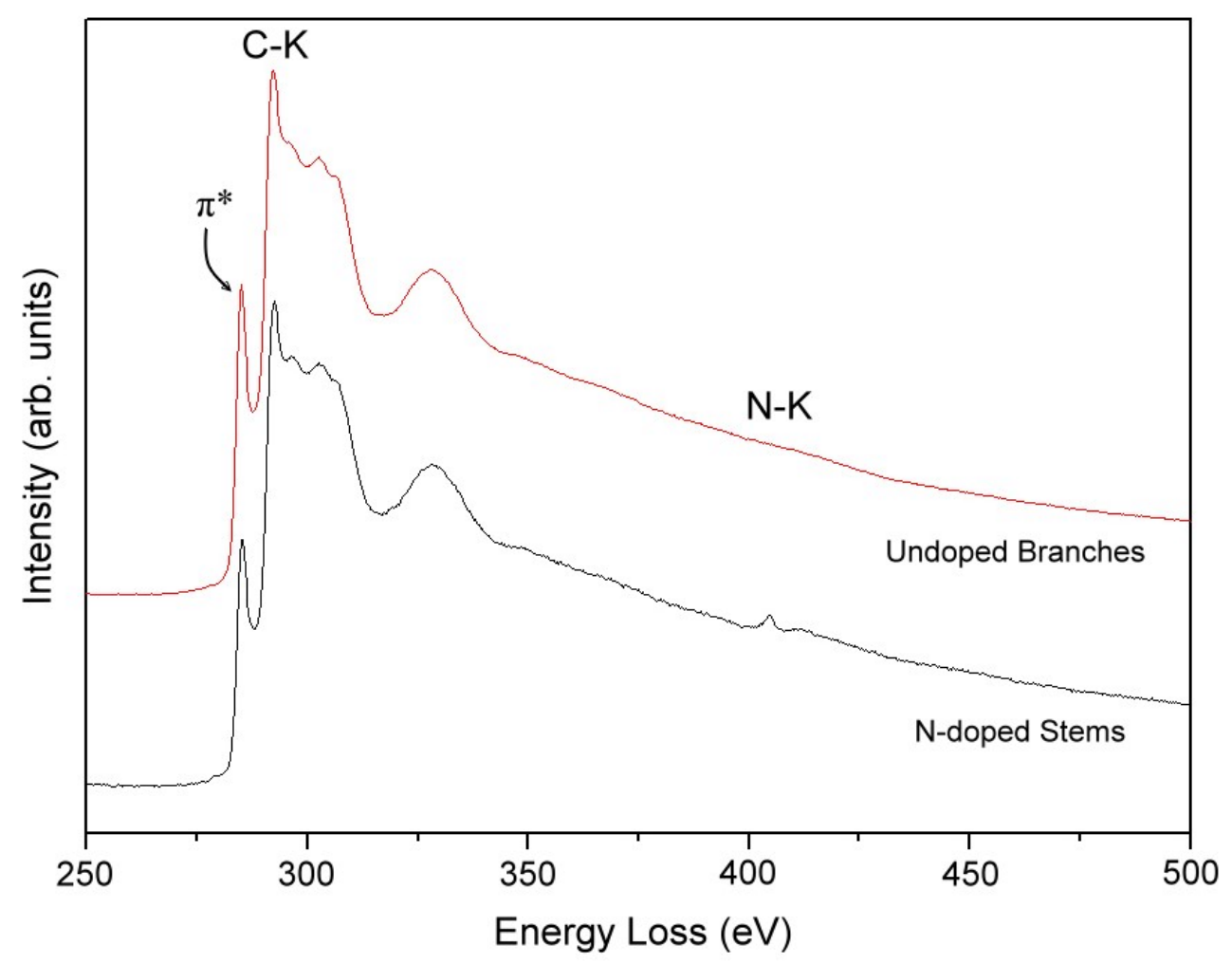




\section{The Experiment section:}

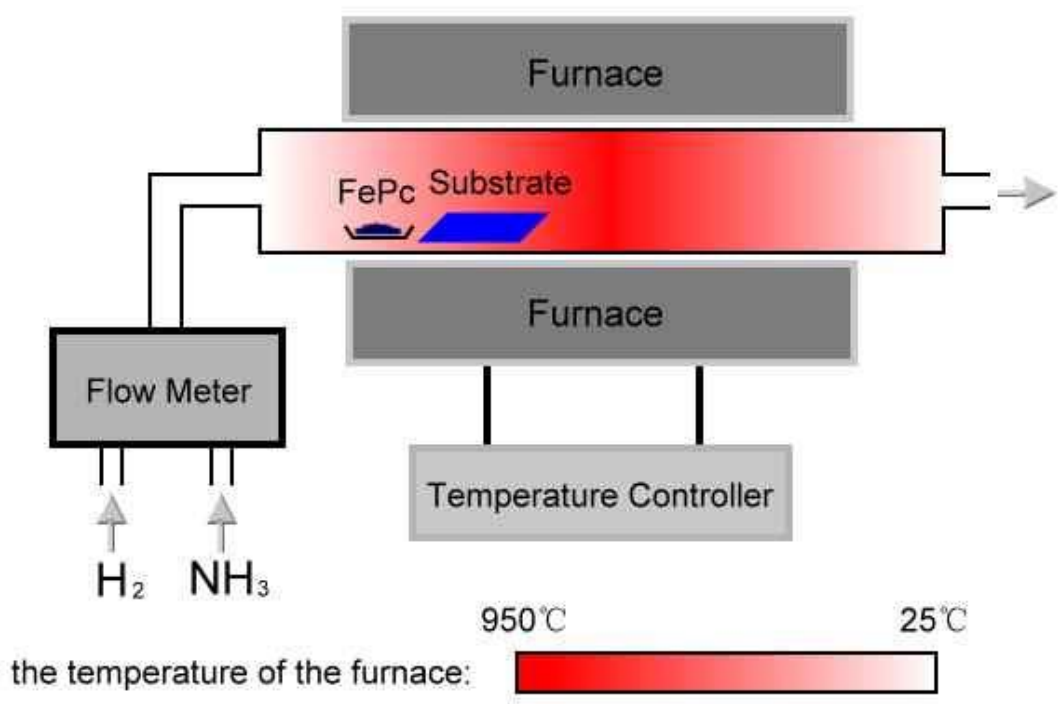

MBCNTs were synthesized by pyrolysis of FePc via a gas-flow fluctuation method in a continuous CVD process. The equipment was illustrated in the Figure above. To synthesize MBCNTs, hydrogen gas $\left(\mathrm{H}_{2}, 99.99 \%\right)$, which could be controlled and measured by flow meter (D08-4B/2M, China), was used as carrier gas through a quartz tube $(0.022 \mathrm{~m}$ inner-tube diameter; $1.3 \mathrm{~m}$ in length). As the temperature at the center of the furnace reached $950 \square$, a quartz boat with $0.05 \mathrm{~g} \mathrm{FePc}$ (New Jersey, USA) was placed in the region of $550 \square$, then FePc was evaporated from the boat and pyrolyzed in high temperature $(650 \square)$ region $0.06 \mathrm{~m}$ downstream where $\mathrm{SiO}_{2}$ substrate for CNT growth was placed. The reaction lasted 12 minutes in a steady flow of $40 \mathrm{sccm} \mathrm{H}_{2}$. And at the 6th minute, we turned up and down the $\mathrm{H}_{2}$ flow randomly by the flow meter, and the gas-flow fluctuated at the moment. The flux of the gas flow, which could be controlled and measured by flow meter, was fluctuated within the range of $100 \mathrm{sccm}$, and this fluctuation process lasted for 15 seconds. After the reaction, the product was annealed at $950 \square$ for 5 minutes to provide sufficient thermal energy to make CNTs into perfectly crystalline structures. Finally, the reactor was cooled to room temperature under $\mathrm{H}_{2}$ ambient after the growth.

Multilevel branched junctions could be obtained by sequential fluctuation. In a typical experiment, the growth lasted for 15 minutes in gas-flow of $40 \mathrm{sccm} \mathrm{H}$, and at the 6th, 8th, 11th minute, the gasflow fluctuated for 15 seconds in a range of $40 \mathrm{sccm}$. The branched junction would just take place at 
these moments. The branch number of each junction could be controlled by the range of flowfluctuation. In the experiment, the fluctuations took place at the 6 th minutes for 15 seconds, and the range of the fluctuation could be in-situ controlled and measured from 10 to $1,000 \mathrm{sccm}$ by the flow meter.

The composition could be controlled by component of gas-flow. To synthesize heterojunctions with undoped branches and $\mathrm{N}$-doped stems, we used $40 \mathrm{sccm} \mathrm{H}_{2}$ as carrier gas in the first 6 minutes, undoped branches formed in this term. In the next 6 minutes, the carrier gas was replaced by $40 \mathrm{sccm}$ $\mathrm{NH}_{3}(99.99 \%)$. The replacement lasted for 15 seconds with a fluctuation within the range of $100 \mathrm{sccm}$. To synthesize heterojunctions with $\mathrm{N}$-doped branches and undoped stems, the process was reversed, that first the $40 \mathrm{sccm} \mathrm{NH}_{3}$ was used, then replaced by $40 \mathrm{sccm} \mathrm{H}_{2}$ at the 6th minute with a fluctuation within the range of $100 \mathrm{sccm}$. To synthesize straight $\mathrm{C} / \mathrm{CNx}$ junctions, there were two routes. One was to replace the flow in the early stage of CNTs growth. In the reaction, we replaced $40 \mathrm{sccm}_{2}$ by 40 $\mathrm{sccm} \mathrm{NH}_{3}$ at the $3 \mathrm{rd}$ minute with a fluctuation of $100 \mathrm{sccm}$. The other route was to replace the flow with a tiny fluctuation. In the reaction, we replaced $40 \mathrm{sccm} \mathrm{H}_{2}$ by $40 \mathrm{sccm} \mathrm{NH}_{3}$ at 6 th minute within a fluctuation of $10 \mathrm{sccm}$.

To synthesize complicated MBCNTs sketched in Fig. 6a, the schedule could be designed that the gasflow was $40 \mathrm{sccm} \mathrm{H}$, $40 \mathrm{sccm} \mathrm{N_{3 }}, 40 \mathrm{sccm} \mathrm{H}$, $40 \mathrm{sccm} \mathrm{N_{3 }}$ sequentially and the replacements took place at the 5 th, 7 th, 11 th minute. At the 7 th minute the replacement was accompanied with a tiny fluctuation (only $10 \mathrm{sccm}$ ) to synthesize the straight $\mathrm{C} / \mathrm{CNx}$ junction, while at the 5 th and 11 th minute, we used the larger fluctuation to obtain the branched $\mathrm{C} / \mathrm{CNx}$ junction between neighbour levels.

The samples were characterized by SEM (Hitachi S-4300, operated at 15 kV), TEM (Hitachi-2010, operated at $200 \mathrm{kV}$ ) and EELS (HRTEM JEOL 2010F equipped with a Gatan PEELS 666 detector). $\mathrm{SiO}_{2}$ substrate with product was splited from the middle, and then SEM was used to examine the profile of CNTs array to characterize the configuration of the CNTs growth.

To measure the electrical properties, we spread samples of $\mathrm{Y}$ junctions with undoped stems and branches on a 500-nm thick thermal oxidized silicon surface between Ti/Au pads that had already been 
prepared with the photolithography method. Using a probe point extension focused-ion-beam (FIB) system (IDS P2X), the surface was visualized using a low beam current (4pA) in order to search the samples. Once found, Pt electrodes were patterned on each terminal of Y junctions. To obtain better contact between the CNTs and the Pt leads, thermal annealing was performed in Ar atmosphere at 350 ${ }^{\circ} \mathrm{C}$ for 20 minutes using a tube furnace. The electrical properties were measured using a probe station (Wentworth Company MP1008) and semiconductor parameter analyzer (Hewlett-Packard 4140B) at room temperature in air.

\section{The effect of gas-flow:}

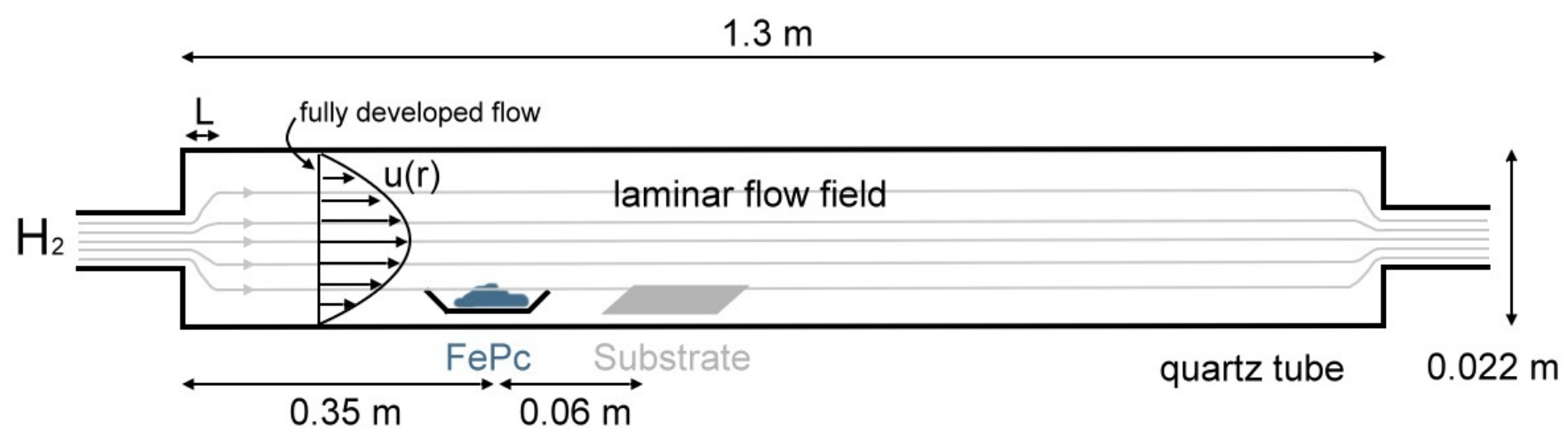

The quartz tube is $0.022 \mathrm{~m}$ in diameter, $1.3 \mathrm{~m}$ in length. The quartz boat is located at the position of $0.35 \mathrm{~m}$ to the entrance, and the substrate for the growth of CNTs is placed $0.06 \mathrm{~m}$ downstream. Without fluctuation, $\mathrm{H}_{2}$ is steady about $40 \mathrm{sccm}$. In this case, the flow can be regarded as compressible viscid Newtonian flows. The Reynolds number $(\mathrm{Re})$, which the stability of flow depends on, can be calculated as follow:

$$
\boldsymbol{R e}=\frac{\mathbf{v d}}{\mathbf{v}}
$$

where $\mathrm{d}$ is the diameter of quartz tube, $\mathrm{v}$ is the flow velocity and $v$ is the kinematic viscosity. The $\mathrm{v}$ and $v$ can be calculated by (2) and (3) respectively:

$$
v=\frac{\Phi}{S}=\frac{\Phi}{\pi \mathbf{r}^{2}}=\frac{4 \Phi}{\pi d^{2}}
$$

where $\Phi$ is the flow flux and the $\mathrm{S}$ is the cross-sectional area. 


$$
v=\frac{\mu_{0}(273+S)}{\rho(T+S)}\left(\frac{T}{273}\right)^{\frac{3}{2}}
$$

where $\mu 0$ is the dynamic viscosity at the $273 \mathrm{~K}(\mathrm{H} 2, \mu 0=8.4 \times 10-6 \mathrm{~Pa} \cdot \mathrm{s}), \rho$ is the density $(\mathrm{H} 2$ at $820 \mathrm{~K}$, $\rho=2.97 \times 10-2 \mathrm{~kg} \cdot \mathrm{m}-3), \mathrm{T}$ is the temperature and $\mathrm{S}$ is an effective temperature called the Sutherland constant $(\mathrm{H} 2, \mathrm{~S}=71 \mathrm{~K})$.

So at the flow flux $(\Phi)$ of $40 \mathrm{sccm}$, the Re can be calculate to be 0.0679 , far below 2000 , then the flow is very stable and can be considered as a laminar flow.

The entrance length $(\mathrm{L})$, which indicates the length of the tube between the entrance and the point where the fully developed flow begins, can be calculated as follow:

$$
\mathrm{L}=\mathbf{0 . 0 5 8 R e} \times \mathbf{d}=0.058 \times 0.0679 \times\left(22 \times 10^{-3}\right) \mathrm{m}=8.7 \times 10^{-5} \mathrm{~m}<<0.41 \mathrm{~m} \text { (4) }
$$

The distance from the growing place of CNTs to the entrance is $0.41 \mathrm{~m}$, much larger than L. So in the area of CNTs growth, the flow is steady and fully developed. The flow velocity distribution in fully developed laminar tube flow is a paraboloid of revolution about the centerline (the Poiseuille paraboloid) as shown in Fig. (a). The wall shear stress is constant and is given by:

$$
\boldsymbol{\tau}_{\mathrm{w}}=\frac{\mathbf{4} \overline{\mathbf{u}} \boldsymbol{\mu}}{\mathbf{r}_{0}}
$$

where $\overline{\mathrm{u}}$ is the average flow velocity, $\mu$ is the dynamic viscosity and $\mathrm{r}_{0}$ is the radius of the quartz tube. According to (5), the wall shear stress will be steady in a laminar flow field.

Moreover, $\operatorname{Re}$ is very small, $\operatorname{Re}<1$, so the flow can be suggested to be creeping flow, where viscous effects predominate and the inertia is negligible. If we regard a CNT with the length of $\mathrm{L}_{\mathrm{CNT}}$ as a vertical column on the substrate, the drag force can be given as:$$
\mathbf{F}=\mathbf{C \mu v L}_{\mathrm{CNT}}
$$

where $\mathrm{C}$ is a constant, and $\mathrm{L}_{\mathrm{CNT}}$ is the length of the CNTs. When the flux is $40 \mathrm{sccm}$ in the experiment, the flow velocity is about $0.18 \mathrm{~cm} / \mathrm{s}$, large smaller than $6 \mathrm{~cm} / \mathrm{s}^{1}$ and $1,000 \mathrm{sccm}^{2}$, at which the ref. 1 and ref. 2 report that the CNTs can be oriented, so the drag force is much smaller in this case than the force reported in ref. 1 and ref. 2. Therefore, the force applied to CNTs and catalyst particles is gentle, oriented and constant, which can't make the catalyst collide with each other.

\section{References}


(1) Xin, H.; Woolley, A. T. Nano Lett. 2004, 4, 1481-1484.

(2) Huang, S.; Cai, X.; Du, C.; Liu, J. J. Phys. Chem. B 2003, 107, 13251-13254. 